\title{
The influence of the applied type of cooling after eight-stage hot compression test on the structure and mechanical properties of TRIPLEX type steels
}

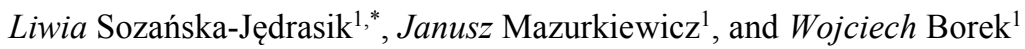 \\ ${ }^{1}$ Silesian University of Technology, Institute of Engineering Materials and Biomaterials, Konarskiego 18A, 44-100 Gliwice, Poland
}

\begin{abstract}
The aim of the work was to analyse the impact of an eight-stage hot compression process carried out on the Gleeble3800 simulator, with three cooling variants after thermo-mechanical treatment of Fe-MnAl-C steels for their structure and mechanical properties. Performed research allowed to evaluate the impact on the structure and properties of simulation conditions for multi-stage rolling of difficult-to-treat thermomechanical steels for which this treatment is the final process of obtaining ready-to-use high-strength construction steels. Applied thermo-mechanical treatment causes that the main process of removing the effects of strain hardening is dynamic recovery, and static and metadynamic recrystallisation taking place after the last deformation but also between successive deformations, which was also confirmed on the basis of structural analysis of the tested steel after different cooling variants. As a result of the eight-stage hot compression test, the ferrite changed its distribution from fine grains occurring at the boundaries of austenite grains after forging, to elongated grains in a perpendicular direction to the compression direction. Isothermal heating at $850^{\circ} \mathrm{C}$ for $30 \mathrm{~s}$ resulted in obtaining a fine-grained structure, statically or metadynamically recrystallised. The maximum tensile strength of the tested steels is about $1250 \mathrm{MPa}$, and the total elongation value is about $27 \%$.
\end{abstract}

\section{Introduction}

Fe-Mn-Al-C steels belong to the group of high-strength low alloy steels (HSLA), additionally characterised by a $15 \%$ lower density than typical structural steels $[1,3,9-$ 16]. Properties such as a good ductility, very good strength properties while maintaining a high yield strength $\left(\mathrm{R}_{\mathrm{p}} / \mathrm{R}_{\mathrm{m}}\right.$ approx. 0.9) make this group of steel attractive for potential applications in structures, especially where it is necessary to reduce the cross sections, and thus the weight of the whole structure $[1,3$, 11-16, 20-23]. Chen, Rana et al. and Bausch, Frommeyer et al. divided the low density steels into four groups: ferritic steels, ferrite-based duplex steels, austenite-based duplex steels and austenitic steels $[3,9,10]$.

Steels with a content of $25-30 \% \mathrm{Mn}$ and $9-12 \% \mathrm{Al}$ and $0.8-1.5 \% \mathrm{C}$ have a microstructure consisting of austenite, ferrite and nano-size carbides $\kappa$ (steel type TRIPLEX) [1, 4-7]. High mechanical properties in this group of steels are attributed to the appropriate composition of elements dissolved in a solid solution together with the precipitate of $\kappa$ carbide coherent with the main phase component such as austenite. To describe the plastic deformation of the $\mathrm{Fe}-\mathrm{Mn}-\mathrm{Al}-\mathrm{C}$ steel with high stacking fault energy (SFE), the concept of deformation induced by shear bands (SIP) and micro band induced plasticity (MBIP) has been introduced [1-4]. Increasing the work hardening rate at the site of the deformation MBIP in steels Fe-Mn-Al-C results from the increase in the total density of dislocations due to the formation of micro bands $[1,2,4]$. During thermo-mechanical treatment of steel with properly selected temperature and deformation conditions, micro additives with high affinity to carbon and nitrogen, i.e. $\mathrm{Nb}, \mathrm{Ti}, \mathrm{V}$ in a concentration of up to about $0.1 \%$, form the dispersed interstitial phase particles of MX-type with $\mathrm{C}$ and $\mathrm{N}$, which limit the growth of recrystallised austenite grains in the intervals between successive plastic deformation steps, e.g. in a multi-pass rolling process and after its completion. Austenite which recrystallised during cooling from a properly selected temperature of the end of hot- working is fragmented, providing high strength properties without the need for expensive heat treatment $[8,10,25]$. According to the research of Chen et al. in Fe-Mn-Al-C steels, recrystallisation occurs during conventional hot rolling process, and the microstructure of the hot-rolled structure has equiaxed austenite grains with annealing twins [9]. The $\mathrm{\kappa}-(\mathrm{Fe}, \mathrm{Mn})_{3} \mathrm{AlC}$ carbides and ferrite after slow cooling locate along the austenite grains boundaries and within the austenite grains. $\kappa$ carbides are then 3-6 times greater than in the case of quickly cooled steels, reducing the conventional yield strength and durability [9]. Bausch, Frommeyer et al. noticed the formation of elongated ferrite strands in the aforementioned steel after hot rolling. The high aluminium content tends to cause the formation of ferrite bands parallel to the rolling direction. Ferrite band concentrated in the midrange, where the concentration of

*Corresponding author: liwia.sozanska-jedrasik@polsl.pl 
the austenite stabilising elements (manganese, coal) is reduced by the negative effect of segregation during solidification. Furthermore, they observed that the recrystallised microstructure of austenite [2, 4]. Fe-Mn$\mathrm{Al}-\mathrm{C}$ steels have a high potential for practical application, despite the many yet not completely understood strengthening mechanisms and the relationship between chemical composition and properties. This work can be a contribution to the discovery of new relationship and correlations, which underlines the importance of quickly translating research results into commercial addressing by key steel producers around the world in order to acquire a new steel group with huge application capabilities. The existing complexity of the deformation mechanisms in this group of steels is a challenge because the characteristics of strain hardening, and the deformation characteristics of austenite and ferrite in Fe-Mn-Al-C steels have not yet been explained in detail $[3,10]$.

Mechanical properties of high-manganese steels can be shaped by appropriately selected thermo-mechanical treatment, which is a beneficial method of producing mass products in economic terms. Thermo-mechanical treatment allows to increase the strength of the material without reducing its ductility [19-26].

\section{Materials and methods}

The material for the research were two newly-developed experimental high-manganese steels of TRIPLEX type X105MnAlSi24-11 (X105 steel) and micro-additives Nb and Ti X98MnAlSiNbTi24-11 (steel X98). The chemical composition of the investigated steels is shown in Table 1.

Table 1. Chemical composition of the investigated steels (according to the ladle chemical analysis).

\begin{tabular}{|c|c|c|c|c|c|c|}
\hline \multicolumn{7}{|c|}{ Steel X98MnAISiNbTi24-11 (X98) } \\
\hline $\mathbf{C}$ & Mn & Al & $\mathbf{S i}$ & $\mathbf{N b}$ & Ti & $\mathrm{Ce}$ \\
\hline 0.98 & 23.83 & 10.76 & 0.20 & 0.048 & 0.019 & 0.029 \\
\hline \multicolumn{2}{|c|}{ La } & \multicolumn{2}{|l|}{ Nd } & $\mathbf{P}_{\max }$ & \multicolumn{2}{|c|}{$\mathbf{S}_{\max }$} \\
\hline \multicolumn{2}{|c|}{0.006} & 0.018 & & 0.002 & \multicolumn{2}{|c|}{0.002} \\
\hline \multicolumn{7}{|c|}{ Steel X105MnAISi24-11 (X105) } \\
\hline $\mathbf{C}$ & Mn & Al & Si & Nb & Ti & $\mathrm{Ce}$ \\
\hline 1.05 & 23.83 & 10.76 & 0.10 & - & - & 0.037 \\
\hline \multicolumn{2}{|c|}{ La } & \multicolumn{2}{|l|}{ Nd } & $\mathbf{P}_{\max }$ & \multicolumn{2}{|c|}{$\mathbf{S}_{\max }$} \\
\hline \multicolumn{2}{|c|}{0.011} & \multicolumn{2}{|c|}{0.015} & 0.005 & \multicolumn{2}{|c|}{0.005} \\
\hline
\end{tabular}

The designed eight-step process of hot-pressing the samples in the form of parallelepipeds with dimensions $15 \times 20 \times 35 \mathrm{~mm}$, simulating the final rolling passages (Fig. 1). The experiment was performed using the thermomechanical treatment simulator Gleeble 3800. Draft coefficient, plastic deformation rates and break times between successive plastic deformations were selected considering the applicable hot-rolling conditions in industrial production. The thermo-mechanical treatment was applied to the samples, maintaining the proportions concerning the width of the sample to the width of the anvil in the range of 6:10. The task of total real deformation equals to 2 allowed for simulation of thermomechanical treatment in conditions close to a flat state of deformation. Figure 2 presents the parameters of an eightstage hot compression process. In variant 330 s isothermal annealing at $850^{\circ} \mathrm{C}$, in order to remove the effects of strain hardening, was used. The actual deformation in the compression test is defined by dependence [24]:

$$
\varphi=\ln \left(\frac{h_{1}}{h_{0}}\right)
$$

where: $\mathrm{h}_{0}$ - the initial height of the sample,, $\mathrm{h}_{1}$ - the final height of the sample.

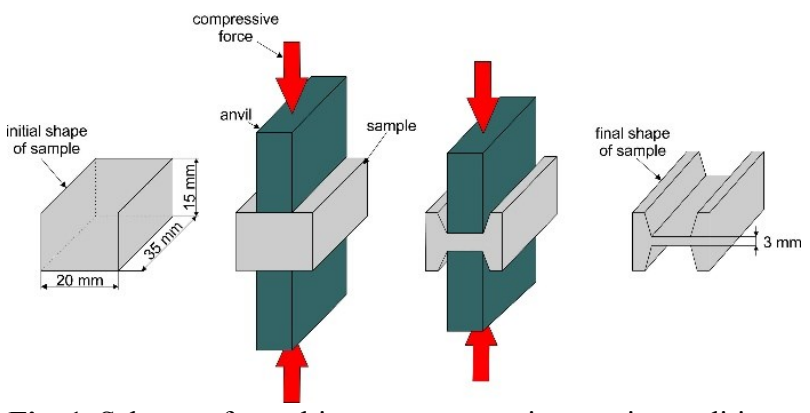

Fig. 1. Scheme of a multi-stage compression test in conditions similar to the flat state of deformation in thermo-mechanical simulator Gleeble 3800.

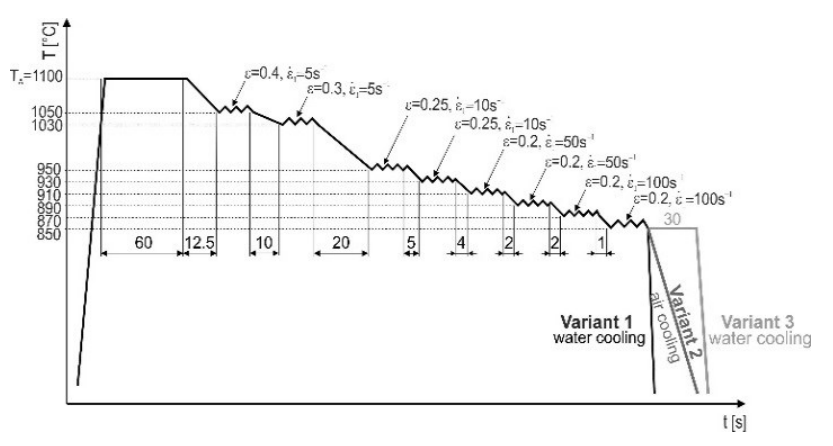

Fig. 2. Scheme of thermo-mechanical processing of plastically deformed samples in the Gleeble 3800 simulator.

Samples for structural investigations by light microscopy and scanning electron microscopy were included, then ground and mechanically polished. In order to reveal the structure as a reagent, a $5 \%$ solution of $\mathrm{HNO}_{3}$ in ethyl alcohol was used. Observations of the structure of the tested steels were made on the light microscope Axio Observer from Zeiss, as well as the scanning electron microscope (SEM) SUPRA 35 from Zeiss, at accelerating voltage $20 \mathrm{kV}$ and using secondary electron detection (SE). In order to examine the chemical and phase composition of the sample, microregions and precipitates, an EDS spectrometer and a diffraction camera were used, coupled with the above-mentioned SEM microscope in the Edax Trident XM4 system.

Tensile strength tests were carried out on samples with a thickness of $1.5 \mathrm{~mm}$, cut from blocks after thermomechanical treatment (Fig. 3a) from the tested steels. The samples were stretched at a speed of $50 \mathrm{~mm} / \mathrm{min}$ on the Z020 testing machine from ZWICK. The results were developed using Zwick's TestXpert II software. For each variant of the thermo-mechanical treatment, three static tensile tests were carried out. The hardness tests were carried out on FM-700 hardness tester from Future-Tech using the Vickers method according to EN ISO 6507-1. The hardness was measured at a load of $4.905 \mathrm{~N}$ (500gf). Hardness test was performed on the longitudinal 
metallographic section with a step of $0.25 \mathrm{~mm}$ (Fig. 3b). 15 hardness measurements were made for each sample.

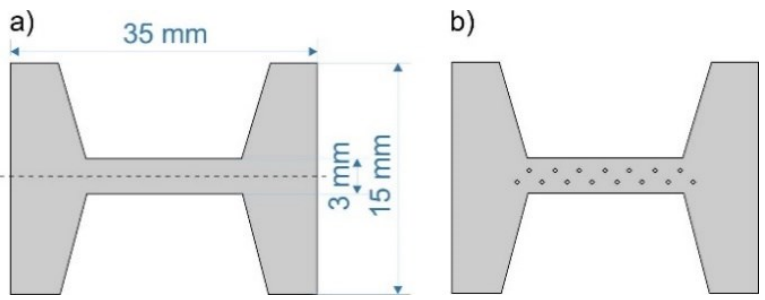

Fig. 3. Sample diagram for static tensile test (a), scheme of imprints location in hardness measurement (b).

The aim of the work was to analyse the influence of the eight-stage hot compression process in a flat deformation system realised with the use of Gleeble 3800 simulator and different cooling variants after finished hot plastic deformation on the structure and mechanical properties of tested Fe-Mn-Al-C steels: X98 and X105 belonging to groups of high-manganese TRIPLEX type steels.

\section{Results and discussion}

\subsection{Plastometric behaviour}

Detailed analysis of the flow curves in the strain-strain system $(\sigma-\varepsilon)$ during one-stage compression of the tested X98 and X105 steels allowed to state that the deformation rate has a significant effect on the flow stress, these values range from 110 to $485 \mathrm{MPa}$ for the applied deformation conditions (Table 2). With the increase of the deformation rate, the shift towards higher values of the limit strain $\varepsilon_{\max }$ corresponding to the maximum value of the flow stress occurs. The deformation temperature has a significant effect on $\varepsilon_{\max }$ (Table 2). The X98 steel at a temperature of $1050{ }^{\circ} \mathrm{C}$ at the highest deformation rate of $10 \mathrm{~s}^{-1}$ obtains a deformation of $\varepsilon_{\max }$ of 0.18 and together with the temperature reduction to $850^{\circ} \mathrm{C}$, the value of $\varepsilon_{\max }$ increases to about 0.25 , i.e. the value of the limit deformation increases by about $40 \%$. However, for the same temperature of $1050^{\circ} \mathrm{C}$ and deformation rate $10 \mathrm{~s}^{-1}$, $\mathrm{X} 105$ steel obtains the value of the limit strain $\varepsilon_{\max } 0.16$, which together with the temperature reduction to $850^{\circ} \mathrm{C}$ increases to the value of about 0.28 . Thus, in the case of X105 steel, the limit of plastic deformation is increased by about $75 \%$. The initiation of dynamic recrystallisation takes place before reaching the strain $\varepsilon_{\max }$, corresponding to the maximum value of the flow stress. For both tested steels at a temperature of $850^{\circ} \mathrm{C}$, after real deformation about 0.2 there is a beginning of dynamic recrystallisation. Formation of a fine structure due to dynamic recrystallisation, under industrial conditions is this possible to achieve provided that these parameters of thermo-mechanical treatment are reproduced on industrial rolling mills [26].

Based on the results obtained in a simulated eight-step compression of the investigated steels (Fig. 4) it was found that the process controlling deformation strengthening in the whole range of plastic forming temperature is dynamic recovery. On the basis of the $\sigma-\varepsilon$ curve analysis for one-stage deformation of the tested steels at $1050{ }^{\circ} \mathrm{C}$ it was assumed that the deformation controlling process will be dynamic recrystallisation. The draft used for the first and second stage of strain in the eight-stage compression was 0.4 and 0.3 , i.e. it was higher than determined in one-stage compression of these samples. On the other hand, the character of the curves for the first and second deformations at $1050^{\circ} \mathrm{C}$ and $1030^{\circ} \mathrm{C}$ respectively indicates that the only process which controls the strain hardening was dynamic recovery. It is associated with a lower deformation rate of $5 \mathrm{~s}^{-1}$ than those obtained in one-step compression tests $\left(10 \mathrm{~s}^{-1}\right)$. Stress values in the first stage of plastic deformation are lower by about $50 \mathrm{MPa}$ as compared to the stress obtained in a one-stage hot compression at $1050^{\circ} \mathrm{C}$ (Table 2, Fig. 4).

Table 2. The influence of temperature and strain rate on the flow stress of tested high manganese TRIPLEX steels [26].

\begin{tabular}{|c|c|c|c|c|c|}
\hline $\begin{array}{c}\text { Strain } \\
\text { temperature }\end{array}$ & $\begin{array}{c}\dot{\boldsymbol{\varepsilon}} \\
{\left[\mathbf{s}^{-1}\right]}\end{array}$ & \multicolumn{2}{|c|}{$\boldsymbol{E}_{\max }$} & \multicolumn{2}{c|}{$\begin{array}{c}\boldsymbol{\sigma} \\
{[\mathrm{MPa}]}\end{array}$} \\
\hline \multirow{4}{*}{$\mathbf{1 0 5 0}^{\circ} \mathbf{C}$} & & $\begin{array}{c}\text { X98 } \\
\text { steel }\end{array}$ & $\begin{array}{c}\text { X105 } \\
\text { steel }\end{array}$ & $\begin{array}{c}\text { X98 } \\
\text { steel }\end{array}$ & $\begin{array}{c}\text { X105 } \\
\text { steel }\end{array}$ \\
\hline & 0.1 & 0.166 & 0.152 & 118 & 110 \\
\cline { 2 - 6 } & 1 & 0.169 & 0.156 & 170 & 159 \\
\cline { 2 - 6 } & 10 & 0.183 & 0.163 & 254 & 238 \\
\hline \multirow{3}{*550}{$\mathbf{C}$} & 0.1 & 0.169 & 0.159 & 175 & 173 \\
\cline { 2 - 6 } & 1 & 0.195 & 0.163 & 257 & 246 \\
\cline { 2 - 6 } & 10 & 0.233 & 0.214 & 363 & 353 \\
\hline \multirow{3}{*}{$\mathbf{8 5 0}^{\circ} \mathbf{C}$} & 0.1 & 0.178 & 0.127 & 310 & 284 \\
\cline { 2 - 6 } & 1 & 0.191 & 0.168 & 384 & 377 \\
\cline { 2 - 6 } & 10 & 0.253 & 0.279 & 485 & 476 \\
\hline
\end{tabular}
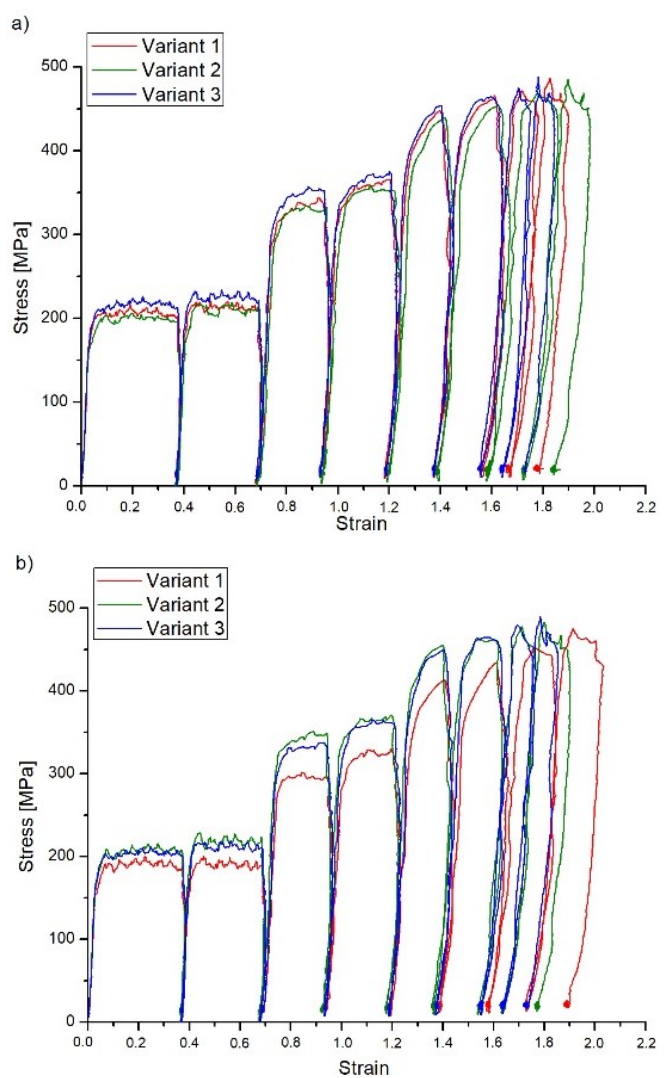

Fig. 4. Stress-strain curves of the eight-step hot compression from X98 (a) and X105 (b) steel, in accordance with the thermo-mechanical treatment diagram shown in Figure 2.

Lowering the temperature of thermo-mechanical treatment to $850^{\circ} \mathrm{C}$ causes the increase of the maximum 
value of the flow stress to about $485 \mathrm{MPa}$ for both steels. The reduction of the real deformation value in the subsequent stages of the eight-stage thermo-mechanical treatment and the reduction of the deformation temperature causes that the process which removes of strain hardening is the static or metadynamic recrystallisation taking place in the intervals between the individual strains [27].

\subsection{Microstructure}

Based on the observation of the structure using light microscopy and scanning electron microscopy, it was found that the steels tested after forging are characterised by austenitic-ferritic structure with the participation of carbides, the description of these investigations is presented in other publications $[17,18]$.

The applied thermo-mechanical treatment consisting of the eight-step hot compression of X98 and X105 steels of TRIPLEX type causes that the main process removing the effects of strain hardening is dynamic recovery, as well as static and metadynamic recrystallisation taking place between successive strains. As a result of the applied thermo-mechanical treatment, the ferrite changed its distribution from fine grains occurring at the boundaries of austenite grains in the forged state, to elongated grains in a direction perpendicular to the compression direction of length from 10 to even $300 \mu \mathrm{m}$ (Fig. 5, Fig. 6). In both studied steels, after the eight-stage compression, numerous annealing twins (Fig. 6) and twins of deformation in austenite grains were observed (Fig. 7). In cooling variants 1 and 3, X98 steel is characterised by a higher grain refinement than X105 steel. However, after the thermo-mechanical treatment and cooling in water, smaller grains were observed in X105 steel, where the average diameter was for steel X98 $\sim 7 \mu \mathrm{m}$ and for steel X105 5.5 $\mu \mathrm{m}$. After 30 seconds of isothermal heating and cooling in water, the grain in both steels was the largest and respectively, the average diameter was for steel X98 $7.5 \mu \mathrm{m}$ and $\sim 13 \mu \mathrm{m}$ for steel $\mathrm{X} 105$.

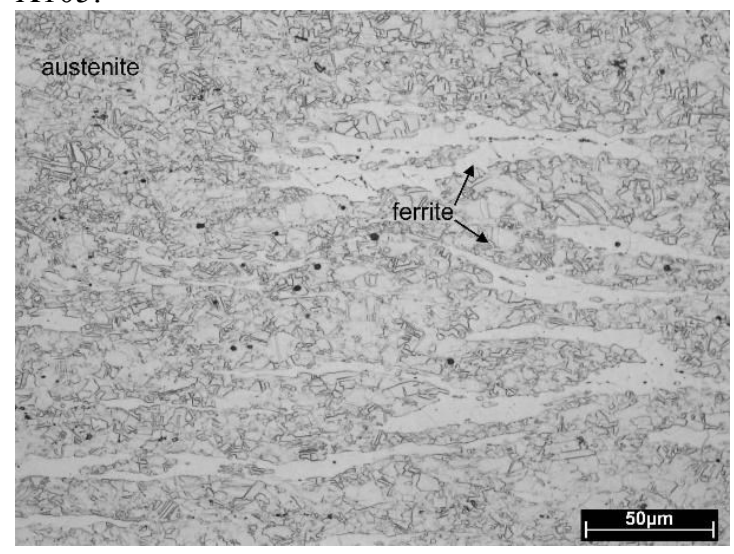

Fig. 5. Microstructure of the X98 steel after the eight-step deformation and cooling according to Variant 1.

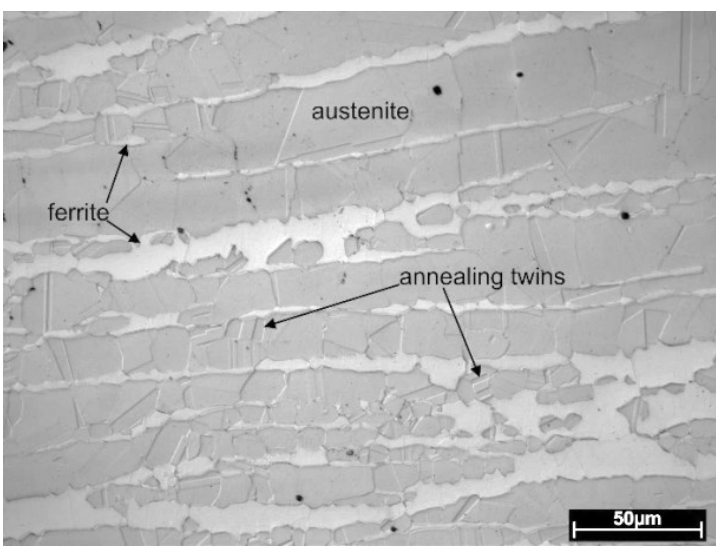

Fig. 6. Microstructure of the X105 steel after the eight-step deformation and cooling according to Variant 3.

Research using scanning electron microscopy equipped with an EDS detector allowed to identify dispersive carbides based on $\mathrm{Nb}$ and Ti in X98 steel. The size of the above carbides visible in both austenite, ferrite and grain boundaries is from a few nanometres to $15 \mu \mathrm{m}$ (Fig. 7a, Table 3) $[17,18]$. Niobium and titanium bonded in carbides effectively inhibit the growth of austenite grains during the thermo-mechanical treatment, which translates into much finer grain in X98 steel than in X105 steel. In the tested steels, the presence of $\kappa$ carbides was found at the boundaries of austenite and ferrite grains, these carbides were also observed in austenite and ferrite grains in the form of nanometric precipitates (Fig. 7, Table 3). In X98 steel the size of $\kappa$ carbides ranges from a few $\mathrm{nm}$ to $200 \mathrm{~nm}$, while in X105 steel carbides with a size of a few nanometres and with a size of approx. $800 \mathrm{~nm}$ appear. In steels cooled in air after the thermomechanical treatment, the largest carbides $\kappa$ were approx. 4 times greater than that of the steel cooled in the water. These carbides can cause steel brittleness during plastic deformation at the room temperature, when large precipitations form at the grain boundaries $[9,10,25]$.

Table 3. Results of the EDS spectrum analysis for points from Fig. 6 (wt. [\%]).

\begin{tabular}{|c|c|c|c|c|c|c|c|}
\hline 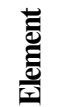 & : & 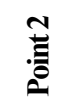 & $\stackrel{\mathscr{B}}{\stackrel{0}{0}}$ & & 華 & 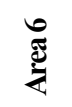 & 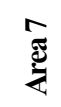 \\
\hline$C^{*}$ & 36.7 & 31.9 & 38.9 & 6.6 & 8.0 & 3.2 & 2.6 \\
\hline$N^{*}$ & 0.8 & 0.7 & 0.3 & 0.4 & 0.6 & 0.2 & 0.5 \\
\hline$A l$ & 7.3 & 6.5 & 0.3 & 12.6 & 11.9 & 9.1 & 12.4 \\
\hline Si & 0.1 & 0.2 & 0.2 & 0.2 & 0.3 & 0.2 & 0.1 \\
\hline$P$ & 0.3 & 0.3 & 0.3 & 0.2 & 0.3 & 0.1 & 0.2 \\
\hline$M n$ & 14.8 & 17.0 & 2.7 & 22.4 & 20.5 & 28.0 & 21.0 \\
\hline$F e$ & 39.3 & 42.2 & 1.3 & 57.6 & 58.5 & 59.3 & 63.2 \\
\hline $\mathrm{Nb}$ & 0.5 & 0.8 & 43.1 & - & - & - & - \\
\hline$T i$ & 0.2 & 0.2 & 12.9 & - & - & - & - \\
\hline
\end{tabular}

*) the content of $\mathrm{C}$ and $\mathrm{N}$ is an approximate value due to the measurement method. 


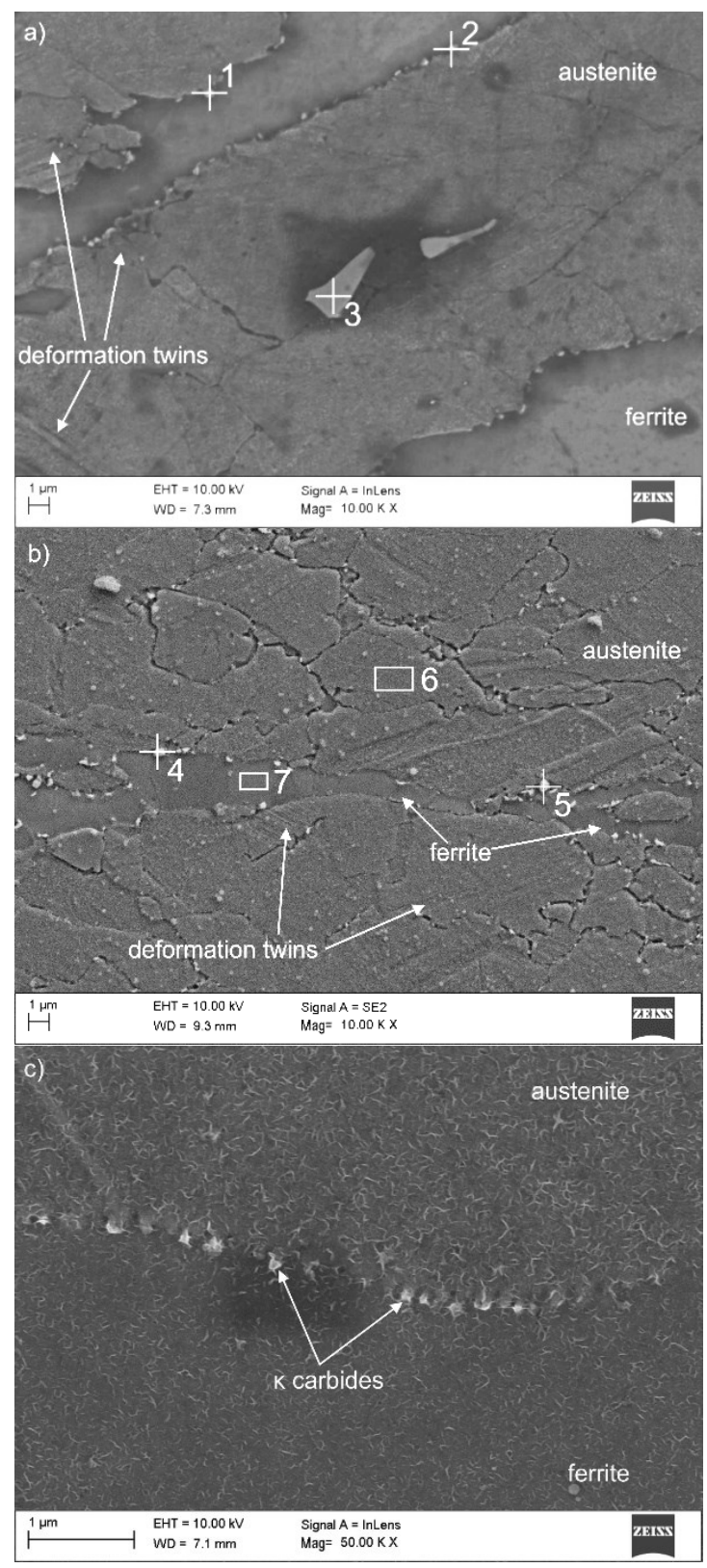

Fig. 7. Microstructure of X98 (a) and X105 (b) steel after the eight-step deformation and cooling according to variant 2 with disclosed carbides together with measurement of chemical composition by EDS (SEM), microstructure of X105 (c) steel after eight-step deformation and cooling according to variant 3 with disclosed $\kappa$ carbides on the grain boundary of austenite and ferrite.

The structures of the investigated steels after the eightstage hot compression and static tensile tests in all cooling variants are characterised by ferrite grains extended in the direction of tensile forces and austenite grains with numerous annealing and deformation twins (Fig. 8). Twins are located in deformed austenite grains, which in the case of X98 steel are more finely divided than in the case of X105 steel. In X98 steel, a comparable volume fraction of ferrite to X105 steel can be observed, which in the initial state after forging in X98 steel was much smaller.
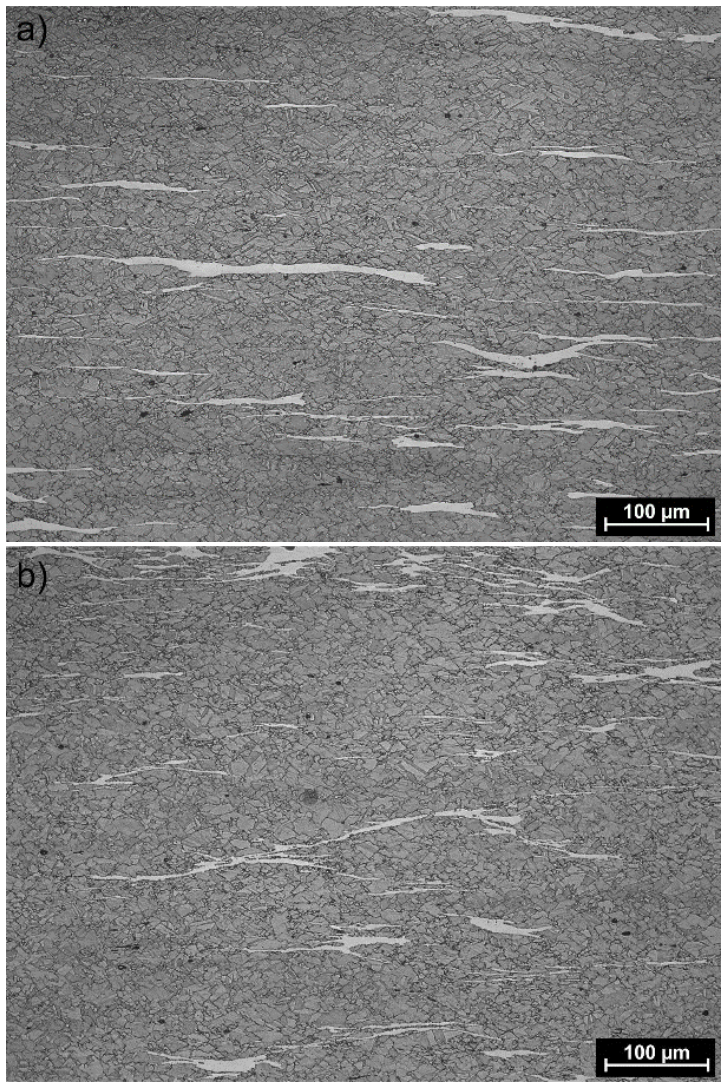

Fig. 8. Microstructure of X98 (a) and X105 (b) steel after eight steps of deformation, cooling according to variant 2 and static tensile test.

\subsection{Results of mechanical properties}

On the basis of the curves obtained from the static tensile test, the tensile strength $R_{m}$ and the elongation $A$ of the tested steel were determined. Analysing figure 9, it was found that the highest strength properties for both X98 and X105 steels were obtained after cooling with variant 2, where tensile strength is in the case of X98 steel - 1254 $\mathrm{MPa}$, while for X105 steel - $1242 \mathrm{MPa}$. Tensile strength of X98 and X105 steels in cooling variants after heat and plastic treatment 1 and 3 is respectively for X98 steel $1113 \mathrm{MPa}$ and $1029 \mathrm{MPa}$, and for X105 steel - $900 \mathrm{MPa}$ and $1065 \mathrm{MPa}$. The highest elongation was obtained for both tested steels after cooling with variant 3 , where its value was $41 \%$ for X98 steel and $35 \%$ for X105 steel. A high elongation of 39\% was also found for X98 steel in cooling with variant 1 . The lowest elongation at high tensile strength was obtained after cooling according to variant 2, where the value of elongation was $28 \%$ for X98 steel, while for X105 steel 26\%. The highest hardness are characterised by steels cooled according to variant 2 , whose value for $\mathrm{X} 98$ steel is $408 \mathrm{HV}_{0.5}$ and $426 \mathrm{HV}_{0.5}$ for $\mathrm{X} 105$ steel. It has been noticed that as the tensile strength increases, the hardness increases but reduces the elongation, which is a typical correlation for these properties in steels. On the basis of hardness tests after static stretching, a gradual increase in hardness was shown along with approaching the fractures, which is caused by increasing strain hardening, e.g. for cooled steel according to variant 2 hardness near the breakthrough was $\sim 470$ HV0.5 for both steels. 


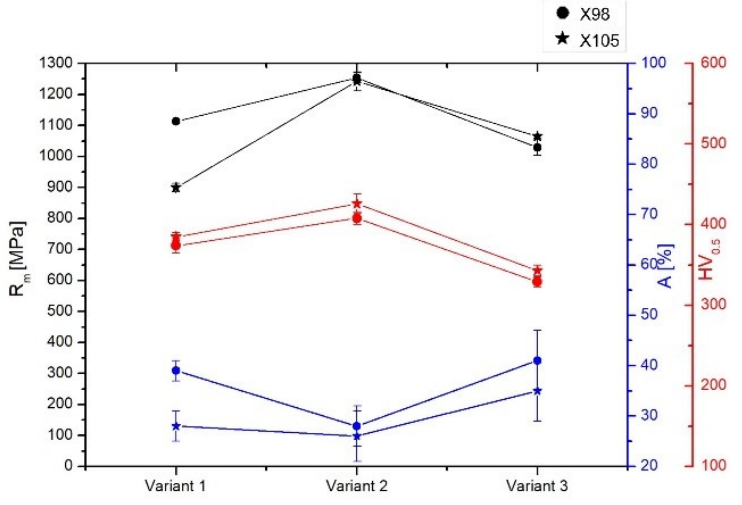

Fig. 9. The values with standard deviation of tensile strength, elongation and hardness of the examined steels after the eightstep hot compression and cooling by cooling three options: 1 - in water, 2 - air, 3 - 30s isothermal heating at $850^{\circ} \mathrm{C}$ and cooling in the water.

\section{Conclusions}

The main processes removing the effects of strain hardening as a result of the eight-stage compression of the tested highmanganese TRIPLEX steels is the dynamic recovery occurring in the first and second stage of plastic deformation, followed by static and metadynamic recrystallisation.

The structure of X98 steel after thermo-mechanical treatment consisting of the eight-step hot compression of TRIPLEX type steels is characterised by greater grain refinement than X105 steel. This is influenced by $\mathrm{Nb}$ and $\mathrm{Ti}$ additions, forming during the plastic deformation, hot dispersive precipitation of carbonitrides and carbides with regular network, limiting the growth of recrystallised austenite grains. Ferrite changed its distribution from fine grains occurring at the boundaries of austenite grains in forged state, to elongated grains in the direction perpendicular to the compression direction after thermomechanical treatment. Research using scanning electron microscopy revealed the presence of complex carbides in austenite, ferrite and grain boundaries. In both tested steels the nanometric $\kappa$ carbides were identified, and in X98 steel carbides based on $\mathrm{Nb}$ and $\mathrm{Ti}$.

The highest tensile strengths tested in each case are obtained after cooling according to variant 2 , where for X98 steel it is $1254 \mathrm{MPa}$ and $1242 \mathrm{MPa}$ for X105 steel. The highest elongation was observed after cooling according to variant 3 , where the value of elongation for X98 steel is $41 \%$, while for X105 steel $35 \%$. It has been noticed that with increasing tensile strength, the hardness also increases but reduces the elongation. On the basis of tests of material hardness after static tensile tests, a gradual increase in hardness was shown along with approaching to the fractures, which is related to the progressive strengthening of steel.

Scientific work was financed in the framework of project funded by the National Science Centre based on the decision number DEC-2012/05/B/ST8/00149.

Liwia Sozańska-Jędrasik is a scholarship holder of the Visegrad International Scholarship Grant for the period September 2017 to July 2018, so some of the research was conducted in collaboration with Ing. Martin Kraus from VŠBTechnical University of Ostrava in the Czech Republic.

\section{References}

1. L. Zhang, R. Song, C. Zhao, F. Yang, Mater. Sci. Eng., A 640 (2015)

2. J.D. Yoo, Mater. Sci. Eng. A Struct. 496 (2008)

3. G. Frommeyer, U. Bruex, Steel Res. Int. 77 (2006)

4. L. Zhang, R. Song, C. Zhao, F. Yang, Y. Xu, S. Peng, Mater. Sci. Eng., A 643 (2015)

5. H. Springer, D. Raabe, Acta Mater. 60 (2012)

6. K. Choi, C. Seo ,H. Lee ,S. K. Kim, J.H. Kwak, K.G. Chin, K.T. Park, N.J. Kim, Scr.Mater. 63 (2010)

7. C.S. Wang, C.N. Hwang, C.G. Chao, T.F. Liu, Scr. Mater. 57 (2007)

8. E. Girault, Mater. Charact. 40 (1998)

9. S. Chen, R. Rana, A. Haldar, R. K. Ray, Prog Mater Sci 89 (2017)

10. M. Bausch, G. Frommeyer, H. Hofmann, E. Balichev, M. Soler, M. Didier, L. Samek, Final Report RFCS Grant No. RFSR-CT-2006-00027 (2013)

11. R.A. Howell, D.C. Van Aken, Iron Steel Tech 6, 4 (2009)

12. D. Raabe, H. Springer, I. Gutierrez-Urrutia, F. Roters, M. Bausch, J.B. Seol, M. Koyama, P.P. Choi, K. Tsuzaki, JOM 66, 9 (2014)

13. H. Kim, D.W. Suh, N.J. Kim, Sci Tech Adv Mater 14 (2013)

14. R. Rana, JOM 66 (2014)

15. Y. Sutou, N. Kamiya, R. Umino, I. Ohnuma, K. Ishida, ISIJ Int 50, 6(2010)

16. I.S. Kalashnikov, O. Acselrad, L.C. Pereira, J Mater Eng Perform 9, 6(2000)

17. L. Sozańska-Jędrasik, J. Mazurkiewicz, W. Borek, L.A. Dobrzański, Mater Eng 38, 2 (2017)

18. L. Sozańska-Jędrasik, J. Mazurkiewicz, W. Borek, K. Matus, Arch Metall Mater 63, 1 (2018)

19. L.A. Dobrzański, W. Borek, J. Mazurkiewicz, Materialwiss Werkst 47, 5-6 (2016)

20. L.A. Dobrzański, W. Borek, J. Mazurkiewicz, Arch Metall Mater 61, 2 (2016)

21. S. Ebied, A. Hamadan, W. Borek, M. Gepreel, A. Chiba, Mater Charact 139 (2018)

22. W. Borek, T. Tanski, Z. Jonsta, P. Jonsta, L. Cizek, METAL 2015: 24th International conference on metallurgy and materials (2015)

23. M. Sroka, A. Zieliński, A. Hernas, Z. Kania, R. Rozmus, T. Tański, A. Śliwa, Metalurgija 56, 3-4 (2017)

24. O. Kwon, K. Lee, G. Kim, K. Chin, Mater. Sci.Forum 638 $642(2010)$

25. I. Gutierrez-Urrutia, D. Raabe, Mater Sci Technol 30, 9 (2014)

26. L. Sozańska-Jędrasik, J. Mazurkiewicz, W. Borek, CRC Press (to be published)

27. E. Kalinowska-Ozgowicz, Open Access Library, 20 (2) 1246(2013) 